\title{
The impact of personality types and gender on attitude towards drinking alcohol in patients with depression
}

\author{
Nishtha Kumar ${ }^{1}$ \\ ${ }^{1}$ Post graduate student, Department of Psychology, Maniben Nanavati Women's College, Mumbai. \\ E-mail-nishthakumar.kumar@gmail.com
}

\begin{abstract}
Background: Personality does play a role in the genesis of both depression and alcohol dependence. It is well known that patients with depression may indulge in alcohol consumption that in turn may lead to dependence. Men generally are more prone to alcohol dependence as a coping mechanism than women. The main purpose of the research was to study the relationship between personality type and gender on attitude towards drinking alcohol in patients with depression.

Methodology: The study utilized a 2x2 design. The sample population was ninety which comprised of females and males and all were s diagnosed with depression. Sample was collected from Delhi, Ahmedabad and Mumbai. The method of purposive sampling was applied and McCroskey Introversion scale was administered and based on the scoring, sample population was divided into gender and personality type. A scale measuring attitude towards alcohol by Bharda and Girija was administered on all four groups of the sample. Analysis was done using a two way analysis of variance.

Results: The findings of the study showed that there was significant effect of personality type (introversion \& extroversion) on attitude towards drinking alcohol. There was also a significant effect of gender (male \& female) on attitude towards drinking alcohol. There was no effect interaction between personality type and gender on the attitude towards drinking alcohol.

Conclusion: Personality and gender play a role in both depression and alcohol dependence and need to be considered when planning treatment and relapse prevention as well as playing a role in the genesis of alcohol dependence and attitudes towards alcohol intake.
\end{abstract}

Key words: personality, depression, gender, male, female, alcohol dependence, introversion, attitudes towards alcohol, extraversion.

(Paper received $-7^{\text {th }}$ December 2015, Peer review completed $-12^{\text {th }}$ March 2016, Accepted $-26^{\text {th }}$ July 2016)

\section{INTRODUCTION}

Depression is a major mental health concern during emerging adulthood [1]. Personality refers to individuals' unique and relatively stable patterns of behavior, thoughts, and feelings [2]. Neuroticism was originally conceptualized as a quantitative personality trait defining an individual's vulnerability to various neurotic disorders and psychological distress. Individuals with high Neuroticism are characterized with emotional instability and are prone to low self-esteem, feelings of anxiety, depression, and guilt [3]. Essau et al. [4] also investigated co-morbid psychological disorders such as depression and somatic problems and found that depressive disorders and somatic disorders accompany substance use disorders in almost 15 percent of the cases. The study concluded that alcohol fulfilled all the characteristics of an access substance to drug use. From the onset of drug consumption and stabilization of drug related psychological and physical disturbances not more than one year passed by females and about two years by males. An examination of the relationship between personality and alcoholism presupposes that clearly identifies dimensions of personality exist and can be agreed upon. This, however, is not necessarily the case. 
Numerous personality traits have been studied, and it is often unclear whether the various traits represent unique, partially over-lapping, or largely overlapping constructs [5].

\section{Gender and personality}

Gender has been reported to have influence on personality traits. Consistent gender differences have been reported for Neuroticism, Psychoticism, Harm Avoidance and Reward-Dependence. Less consistent gender- related differences have been established for Impulsivity and Sensation-Seeking. Women generally score higher on Neuroticism, Harm-Avoidance and Reward-Dependence and mens core higher on Psychoticism and some measures of Impulsivity and Sensation Seeking [6-8].

\section{Gender and alcoholism}

Alcoholism is a male-predominated disorder. Most epidemiological studies of the last two decades have found that the rates of alcohol abuse and dependence were about five times higher in men than in women. Schmidt [9] documented differences in the development of alcoholism in alcohol-dependent women and men. Patients who had gone into alcohol dependence treatment for the first time were examined. His data shows that men pass through the central stages of alcoholism significantly earlier than women. Mann and Ackermann [10] reported gender specific differences between women and men dependent on alcohol. The most important result of that study is the remark that on an average, women become dependent on alcohol later than men. However, they then develop resultant ravages faster than men, although the resultant ravages from alcohol dependence are comparable between both women and men. This effect is called the 'telescoping of alcoholism in women'.

\section{Personality and alcoholism}

There are a number of ways that personality and alcoholism can be related to each other [11]. Several personality characteristics - primarily Neuroticism, Impulsivity Disinhibition and Sensation-Seeking have been found to correlate with risk for alcoholism, pre-alcoholism or clinical alcoholism [12-13].

\section{Personality, Gender and Alcoholism}

The relationship between gender and personality is a seldom discussed topic in alcoholism research. An example for the consideration of the interaction between gender, personality and alcoholism is the differentiation of type 1 and type 2 alcoholics introduced by Cloninger [14]. Type 1, found in both female and male alcoholics, has a later age of onset, a psychological dependence on alcohol that leads to a loss of control over drinking after periods of abstention, and guilt and fear engendered by the alcoholic dependence. Type 2, found primarily in men, is characterized by an inability to abstain at all, and by fights and arrests when drinking. Cloninger's classification specifies three personality traits distinguishing Type 1 and Type 2 alcoholics: The Type 1 personality is characterized as low in Novelty- Seeking, high in HarmAvoidance, and high in Reward- Dependence. In contrast, Type 2 personality is high in Novelty-Seeking, low in Harm-Avoidance, and low in Reward-Dependence.

Personality traits are genetic characteristics measured along a continuum. An individual can have a small amount of a trait, a large amount of a trait, or anything in- between. The promoters of traits focus on the fact that researchers can measure variation in a characteristic [15]. Personality types are innate characteristics that are discontinuous with an absolute midpoint. An individual will be placed into a dichotomous category, usually consisting of opposing characteristics such as introversion or extraversion.

The main purpose of this research is to study the relationship of personality characteristics and gender on attitude towards alcohol in patients suffering from depression. In this study, the independent variables are personality type (introversion)(extroversion)and second independent variable is Gender(male)(female) and dependent variable is attitudes towards drinking alcohol. 


\section{METHODOLOGY}

\section{Operational Definitions}

Introverts: Participants who were above the range of 48 as given by MC Croskey's Introversion scale (1997) were classified as introverts.

Extroverts: Participants who were below the range of 21 as given by MC Croskey's Introversion scale (1997) were classified as extroverts.

Attitude Towards Drinking Alcohol: It refers to the scores ranging from low to high that the students obtained in response to the statements in attitude towards drinking alcohol scale.

Depression: Participants who were already clinically diagnosed and undergoing treatment for depression were taken.

\section{Hypotheses}

The hypotheses of this study are:

1. Personality Type (Introversion \& Extroversion) will have a significant difference on attitude towards alcohol consumption in people suffering from depression.

2. Gender (male \& female) will have a significant difference on attitude towards alcohol consumption in people suffering from depression

This research study was created based upon certain assumptions regarding voluntary participation, language comfort, accuracy in translation and representativeness of the sample.

\section{Procedure}

Ninety patients diagnosed with depression undergoing treatment were selected from Ahmedabad, Mumbai and Delhi and then personality type was measured using scale of introversion by McCroskey [16] on males and females ( 47 males \& 43 females) then attitude towards drinking alcohol was measured by using scale given by Bharda \& Girija [17], scores of all scales were taken and further classified into categories of male introvert, male extrovert, female introvert, female extrovert.

\section{Sampling strategy}

The method of purposive sampling was carried out and further classification was done on the basis of introverts and extroverts categories.

Scales used in the measurement

1. McCroskey Introversion Scale: It is an 18 item likert scale. The correlations of this measure with the PRCA-24 have been around .30. Alpha reliability estimates have been above 0.8 [16].

2. Attitude towards drinking Alcohol Scale: It is a likert scale including 34 items with five ratings on it. Split half reliability coefficient is 0.84 , test retest reliability coefficient is 0.74 . Validity coefficient between attitude and beliefs ranges from 0.28 to 0.38 , construct validity coefficient between attitude and using behavior is 0.51 [17].

\section{STATISTICAL ANALYSIS}

The SPSS trial version 20.0 for Windows 8 was applied in order to find out results. The Design of the study is a 2 (personality type) $\times 2$ (gender) factorial design because there are two independent variables. The first independent variable personality type has two levels, introversion and extroversion. The second independent variable has two levels, that is, gender, male and female and we measured there impact on attitude towards alcohol, which is the dependent variable.

\section{RESULTS}

Before any analysis, median split was done and sample population was divided in two groups of introverts and extroverts. The means and standard deviations for all variables are reported in Table 1. 
Table 1: Means, Standard Deviations, for personality Type and Gender Male and Females

\begin{tabular}{|c|c|c|c|c|}
\hline Gender & $\begin{array}{c}\text { Personality } \\
\text { Type }\end{array}$ & Mean & Std. Deviation & N \\
\hline \multirow{3}{*}{ Male } & Extrovert & 109.5833 & 20.22464 & 24 \\
\cline { 2 - 5 } & Introvert & 123.2609 & 18.91901 & 23 \\
\cline { 2 - 5 } & Total & 116.2766 & 20.57827 & 47 \\
\hline \multirow{3}{*}{ Female } & Extrovert & 92.2917 & 13.25167 & 24 \\
\cline { 2 - 5 } & Introvert & 102.0526 & 18.43449 & 49 \\
\cline { 2 - 5 } & Total & 96.6047 & 16.30533 & 48 \\
\hline \multirow{3}{*}{ Total } & Extrovert & 100.9375 & 19.03793 & 42 \\
\cline { 2 - 5 } & Introvert & 113.6667 & 21.34006 & 90 \\
\cline { 2 - 5 } & Total & 106.8778 & 21.02317 & \\
\hline
\end{tabular}

Levene's test confirmed the homogeneity of variances and hence we used a two way analysis of variance for the comparison. A two way ANOVA was run for the sample of ninety participants, conducted for personality characteristics and gender. Results indicate significant difference between the means of introvert and extrovert and the means of male and female. But no significant difference between the means for interaction effect can be seen (Table 2).

Table 2: Two Way Analysis Of Variance

\begin{tabular}{|c|c|c|c|c|c|}
\hline Source & $\begin{array}{c}\text { Type III Sum of } \\
\text { Squares }\end{array}$ & df & Mean Square & F & p-value \\
\hline Corrected Model & $11897.482^{\mathrm{a}}$ & 3 & 3965.827 & 12.430 & 0.0001 \\
\hline Intercept & 1016979.428 & 1 & 1016979.428 & 3187.538 & 0.0001 \\
\hline Gender & 8260.234 & 1 & 8260.234 & 25.890 & 0.0001 \\
\hline $\begin{array}{c}\text { Personality type } \\
\text { (Intro-Extro) }\end{array}$ & 3061.489 & 1 & 3061.489 & 9.596 & 0.003 \\
\hline $\begin{array}{c}\text { Gender * } \\
\text { personality ((Intro- } \\
\text { Extro) }\end{array}$ & 85.484 & 1 & 85.484 & .268 & 0.606 \\
\hline Error & 27438.174 & 86 & 319.049 & & \\
\hline Total & 1067393.000 & 90 & & & \\
\hline Corrected Total & 39335.656 & 89 & & & \\
\hline a. R Squared = .302 (Adjusted R Squared $=.278)$ & & & & \\
\hline
\end{tabular}

As three cities were compared and parametric statistics was carried out for other variables, one way ANOVA was used to compare the significance of difference between the mean of attitude towards alcohol consumption score for the different cities. Results showed there was no significant difference in the attitude towards alcohol use across all three cities. 
Table 3: One Way Analysis Of Variance comparing attitudes towards alcohol consumption across all cities

\begin{tabular}{|c|c|c|c|c|c|}
\hline & Sum of Squares & df & Mean Square & F & p-value \\
\hline Between Groups & 671.756 & 2 & 335.878 & 0.756 & 0.473 \\
\hline Within Groups & 38663.900 & 87 & 444.413 & & \\
\hline Total & 39335.656 & 89 & & & \\
\hline \multicolumn{7}{|c|}{$\left({ }^{*} \mathrm{p}<0.05 .{ }^{* *} \mathrm{p}<0.01\right)$}
\end{tabular}

According to Hypothesis 1, personality characteristics (introvert/extrovert) did have a significant effect on attitude towards alcohol consumption, which matches the findings of the studies discussed above. Hypothesis 2 was also proved as there was a significant gender difference for alcohol consumption. However there was no significant interaction between personality type and gender and hence this Hypothesis was not proved.

\section{DISCUSSION}

The purpose of this study was to examine the effect of personality type (introvert/extrovert) on attitude towards alcohol consumption, to explore gender differences in attitude towards alcohol consumption, and to study the interaction effect of personality type and gender on attitude towards alcohol consumption in patients with depression. As proposed, personality type (introvert/extrovert) had significant effect on attitude towards drinking alcohol. Hence, results were also consistent with the hypothesis and showed that introvert personality type had a significant effect on attitude towards drinking alcohol. As proposed also gender had significant effect on attitude toward drinking alcohol and results showed that male gender had a significant effect on attitude towards drinking alcohol. However, there was no interaction effect between personality type and gender on attitude towards drinking alcohol.

Consistent with previous researches it has shown that a variety of personality characteristics greatly affect drinking levels. The personality trait that was found to be the single best predictor variable is extroversion [18]. As hypothesized that personality type (introvert/extrovert) will have significant effect on attitude towards drinking alcohol, and many studies also supported it and are in line with current study. A study has reported that alcohol that is consumed is positively correlated with extroversion and sociability [19]. Likewise, non-drinkers were found to score lower on levels of extroversion [20]. Leppin, [21] observed that personality variables are also complex in their nature. Personality variables [22] provide better predictions of the environment factors also determine the attitude towards alcohol in a higher way.

It was seen in another study done by Chunkappura [23] on alcoholism and personality that the alcoholics differ significantly from non alcoholics with regard to their attitude towards family unit, sex, self concept, extroversion- introversion and neuroticism- stability. Results also indicated that alcoholics were introverted and had significantly high anxiety.

Another study done by Brown and Munson [24] showed that Alcohol expectancy scores were found to vary with drinking behavior and personality measures; however, no significant sex differences were obtained. Extroverted students expected more social and physical pleasure, more relaxation and less arousal with drinking.

Higher incidence of alcohol use among male when compared to female has been found in various studies [25-26]. Also, many studies showed that males tend to have more positive attitude towards alcohol than females and gender plays a greater role in attitude towards alcohol especially in country like India where it is a male dominated society and a patriarchal society and various researches have shown similar results. Several studies [27] have shown similar results men drank more than did women in bars and public places as well as at private parties and also men had more positive attitude towards drinking alcohol. It appears that attitude towards alcohol consumption mimics the same patterns in depressed and non-depressed populations.

It can be concluded that consumption of alcohol is a function of both personality type and gender. However, the impact is singular and not based on the interaction between personality type and gender. 


\section{Limitations}

Since the size of sample is very small, it may not represent the universe and the inference drawn from the population may be misleading. The data was collected through self report questionnaires only some individuals were comfortable with English and Hindi questionnaires whereas especially in Mumbai and Ahmedabad, many people preferred Marathi and Gujarati questionnaires. This sample comprised of individuals from Mumbai and Delhi and Ahmedabad which can be a problem in generalizing due to huge cultural factors, level of education, living standards, life style, language differences which was different for these cities. Thus the data collected is not a representative sample of the population. Lastly, the median split was used to divide the population into two equal halves and hence it may not a very appropriate method of categorizing the sample and the special characteristics of ambiverts and their relation to attitude towards alcohol may be undiscovered.

\section{Implications for Practice and Research}

The findings of this study have several implications for mental health practitioners, educators and researchers, as the findings of current study shows that introvert males and females both have a positive attitude towards alcohol specially when suffering from depression and preferably when under depression and are bound to get under alcohol abuse in these kind of situations hence, some good intervention programs which can help them and cope with situations effectively can be made and implemented especially targeting the introvert population.

Conceptualization regarding alcoholics and people who engage in alcoholism under stress and severe depressive conditions needs to be based on research that examines the inter-relationships of a broad array of variables. Personality characteristics and the type and severity of parental alcohol dependency likely had differential effects on family functioning. Researchers must grapple with definitional issues regarding alcoholics and move beyond a general, all-inclusive definition of parental alcohol dependency toward a more specific and meaningful categorization. Hence, significantly more research is needed regarding the effects of alcoholism and personality characteristics among persons from diverse ethnic and cultural backgrounds including different cities and even across countries who have historically been under represented in studies, and who have been traditionally under served as there is enormous cross-cultural variation in different countries also. Hence, it also opens a scope for anthropologists and ethnographer for further research on alcohol and differences among cultures. To provide effective interventions (and to enhance resiliency), we must continue to broaden and deepen our understanding of alcoholics and personality characteristics at each opportunity.

\section{REFERENCES}

1. Enns MW, Cox BJ. Personality dimensions and depression: review and commentary. Can J Psychiatry 1997;42(3):274-84.

2. Zuckerman M. Good and bad humors: Biochemical bases of personality and its disorders. Psychol Sci 1995;1:325-32.

3. Eysenck HJ. Creativity as a product of intelligence and personality. In International Handbook of Personality and Intelligence, Springer US ; 1995 : 231-47.

4. Fu Q, Heath AC, Bucholz KK, Nelson E, Goldberg J, Lyons MJ, True WR, Jacob T, Tsuang MT, Eisen SA. Shared genetic risk of major depression, alcohol dependence, and marijuana dependence: contribution of antisocial personality disorder in men. Archives of General Psychiatry. 2002 Dec 1;59(12):1125-32.

5. Cloninger CR, Sigvardsson S, Bohman M. Childhood personality predicts alcohol abuse in young adults. Alcohol Clin Exp Res 1988;12(4):494-505.

6. Loukas A, Krull JL, Chassin L, Carle AC. The relation of personality to alcohol Abuse/Dependence in a High-Risk sample. J Personality 2000;68(6):1153-75.

7. Chassin L, Flora DB, King KM. Trajectories of alcohol and drug use and dependence from adolescence to adulthood: the effects of familial alcoholism and personality. J Abnorm Psychol 2004;113(4):483-9.

8. Kessler RC, Crum RM, Warner LA, Nelson CB, Schulenberg J, Anthony JC. Lifetime co-occurrence of DSM-III-R alcohol abuse and dependence with other psychiatric disorders in the National Comorbidity Survey. Arch Gen Psychiatry 1997;54(4):313-21. 
9. Sander T, Harms H, Lesch KP, Dufeu P, Kuhn S, Hoehe M, Rommelspacher H, Schmidt LG. Association analysis of a regulatory variation of the serotonin transporter gene with severe alcohol dependence. Alcohol Clin Exp Res 1997;21(8):1356-9.

10. Mann K, Hermann D, Heinz A. One hundred years of alcoholism: the twentieth century. Alcohol Alcohol 2000;35(1):10-5.

11. Sher KJ, Gotham HJ. Pathological alcohol involvement: A developmental disorder of young adulthood. Dev Psychopathol 1999;11(04):933-56.

12. Zucker RA, Boyd GM, Howard J, editors. The development of alcohol problems: Exploring the biopsychosocial matrix of risk. US Department of Health and Human Services, Public Health Service, National Institutes of Health, National Institute on Alcohol Abuse and Alcoholism; 1994.

13. Sher KJ, Trull TJ. Personality and disinhibitory psychopathology: alcoholism and antisocial personality disorder. J Abnorm Psychol 1994;103(1):92-7.

14. Cloninger CR. A systematic method for clinical description and classification of personality variants: A proposal. Arch Gen Psychiatry 1987;44(6):573-88.

15. Torgersen S, Vollrath M. Personality types, personality traits, and risky health behavior. Handbook of Personality and Health ; Wiley, UK ; 2006: Pp 215-33.

16. Sallinen-Kuparinen A, McCroskey JC, Richmond VP. Willingness to communicate, communication apprehension, introversion, and self-reported communication competence: Finnish and American comparisons. Commun Res Rep 1991;8(1):55-64.

17. Girija PR, Bhadra BR. A scale to measure attitude towards drinking alcohol. Asian Journal of Psychology \& Education. 1983.

18. Marsh JC, Cao D, D'Aunno T. Gender differences in the impact of comprehensive services in substance abuse treatment. J Subs Abuse Treat 2004;27(4):289-300.

19. Cook M, Young A, Taylor D, Bedford AP. Personality correlates of alcohol consumption. Personal Individ Diff 1998;24(5):641-7.

20. Rodgers B, Korten AE, Jorm AF, Jacomb PA, Christensen H, Henderson AS. Non-linear relationships in associations of depression and anxiety with alcohol use. Psychol Med 2000;30(02):421-32.

21. Richter M, Leppin A, Gabhainn SN. The relationship between parental socio-economic status and episodes of drunkenness among adolescents: findings from a cross-national survey. BMC Public Health 2006;6(1):1.

22. Ashton $\mathrm{CH}$, Kamali F. Personality, lifestyles, alcohol and drug consumption in a sample of British medical students. Med Educn 1995;29(3):187-92.

23. Vuchinich RE, Tucker JA. Alcoholic relapse, life events, and behavioral theories of choice: A prospective analysis. Exp Clin Psychopharmacol 1996b;4(1):19-25.

24. Brown JM, Miller WR. Impact of motivational interviewing on participation and outcome in residential alcoholism treatment. Psychol Addict Behav 1993;7(4):211-8.

25. Grant BF, Harford TC, Dawson DA, Chou PS, Pickering RP. The Alcohol Use Disorder and Associated Disabilities Interview Schedule (AUDADIS): reliability of alcohol and drug modules in a general population sample. Drug Alcohol Depend 1995;39(1):37-44.

26. Dakof GA. Understanding gender differences in adolescent drug abuse: Issues of comorbidity and family functioning. J Psychoactive Drugs 2000;32(1):25-32.

27. Brady KT, Randall CL. Gender differences in substance use disorders. Psychiatr Clin North Am 1999;22(2):241-52.

$$
\begin{aligned}
& \text { Acknowledgements - Nil } \\
& \text { Source of Funding - Nil } \\
& \text { Conflict of Interest - Nil }
\end{aligned}
$$

